\title{
Preventing optimific wrongings
}

\author{
THOMAS SINCLAIR \\ Wadham College, University of Oxford
}

Most people believe that the rights of others sometimes require us to act in ways that have even substantially sub-optimal outcomes, as viewed from an axiological perspective that ranks outcomes objectively. Bringing about the optimal outcome, contrary to such a requirement, is an 'optimific wronging'. It is less clear, however, that we are required to prevent optimific wrongings. Perhaps the value of the outcome, combined with the relative weakness of prohibitions on allowing harm as compared to those against doing harm, justifies nonintervention. In this article, I consider arguments to that effect, focusing on a recent paper in this journal by Andreas Mogensen. I argue that while we do not, in general, do wrong in failing to prevent optimific wrongings, we are nevertheless not permitted, in key cases, to refrain from intervening on the grounds that not intervening will secure the optimal outcome.

\section{INTRODUCTION}

At any given moment, a wide range of outcomes may be accessible via an agent's action or inaction. Suppose that the outcomes can be ranked from best to worst in an objective axiology in the way that consequentialists characteristically suppose they can be. For example, outcomes including many deaths might be ranked lower than outcomes including fewer deaths, all other things equal. Call the best of the accessible outcomes the optimific outcome. Most people think it can be morally wrong to act so as to bring about the optimific outcome. People's rights get in the way, and must be respected even if the optimific outcome is quite a bit better (according to the axiology) than the 
best outcome that can be brought about without transgressing anyone's rights. So, for example, most people think your actions in the following case are morally wrong.

FOOTBRIDGE A runaway trolley is on course to hit five people whom it will crush to death. You are on a footbridge overhead. In order to prevent the five from dying, you push a hiker wearing a heavy backpack into the path of the trolley. Their combined weight will bring the machine to a halt, but the hiker is crushed to death. There was no other way to save the five. ${ }^{1}$

Let us grant that it is indeed wrong to push the hiker into the path of the trolley. Now, would it also be wrong not to stop someone else pushing the hiker into the path of the trolley? What should you do, in other words, in the following kind of case?

FOOTBRIDGE $^{*} \quad$ A runaway trolley is on course to hit five people whom it will crush to death. We are on a footbridge overhead. In order to prevent the five from dying, you or I might push a

\footnotetext{
${ }^{1}$ Adapted slightly from Andreas L. Mogensen, 'Should We Prevent Optimific Wrongs?', Utilitas 28 (2016), pp. $215-226$, at $215-216$. The example is a variation on one originally due to Judith Jarvis Thomson; see her ‘The Trolley Problem', Yale Law Journal 94 (1985), pp. 1395-1415, at 1409 .
} 
hiker wearing a heavy backpack into the path of the trolley. Their combined weight will bring the machine to a halt, but the hiker will be crushed to death. There is no other way to save the five. You see that I am just about to push the hiker onto the tracks. You could stop me at no cost to yourself. ${ }^{2}$

Discussing cases like this, some philosophers report an intuition that you ought to intervene to prevent the wrongdoing: that it would be morally wrong not to intervene. ${ }^{3}$ One of them is Andreas Mogensen. ${ }^{4}$ However, Mogensen distrusts the intuition. He argues that it is permissible not to intervene. We should not perform 'optimific wrongings' ourselves, but we don't have to stop others from performing them. ${ }^{5}$ And this may have important practical implications. For instance, it may turn out that even if embryo experimentation is morally wrong

${ }^{2}$ Adapted from Mogensen, 'Optimific Wrongs', p. 216.

${ }^{3}$ The two cited by Mogensen are Frances Kamm, 'Rights beyond Interests, in her Intricate Ethics (Oxford, 2007), pp. 237-84, at 252; and Jeff McMahan, 'Intention, Permissibility, Terrorism and War', Philosophical Perspectives 23 (2009), pp. 345-72, at 350.

${ }^{4}$ Mogensen, 'Optimific Wrongs', p. 217.

${ }^{5}$ Mogensen uses the term 'optimific wrong' rather than 'optimific wronging'. But the cases that interest both of us are cases of violations of Hohfeldian claims. Intervention to prevent wrongs that are not also wrongings (if any there be) in this sense are not the focus. So I use the term 'optimific wronging', even though it's much clunkier. 
because it involves violating the rights of human beings, we need not try to stop it, if it ultimately leads to better outcomes. ${ }^{6}$

In this paper, I analyse and reject Mogensen's argument. I note a first problem with it in sections 2-4 below, which is that it targets a position that hardly anyone holds. For hardly anyone thinks that we act wrongly in failing to prevent every optimific wronging, and, as I point out, there is good reason for this. But, as I go on to explain, a more narrowly focused argument can be extracted from Mogensen's, according to which we are not required to intervene to prevent optimific wrongings in the kinds of cases that are familiar from discussions of the Doctrine of Double Effect (DDE), such as the case of pushing an innocent man off a footbridge into the path of an onrushing train in order to prevent it from hitting five innocent others. This conclusion really is controversial: many people will think that a bystander ought to intervene to prevent the sacrifice of the one to the greater good in such cases.

In sections 5-8, I reject the narrower argument too. First (in sections 5-6) I reject Mogensen's defence of the claim that you ought not to intervene to prevent the death of an innocent stranger in a key case (TRACKS) that Mogensen appeals to. Then (in sections 7-8) I grant Mogensen's claims about TRACKS for the sake of argument, but contest the inference he draws from those claims to conclusions about preventing optimific wrongings in DDE-type cases. My argument here appeals to the idea that in these cases, non-intervention can make an agent complicit in the wronging. I conclude that even though nonintervention would be an allowing rather than a doing, the complicity may be

\footnotetext{
${ }^{6}$ Mogensen, 'Optimific Wrongs', p. 218.
} 
sufficiently morally problematic to require intervention, despite the absence of any more general requirement to prevent optimific wrongings.

\section{THE BASIC ARGUMENT}

I will call Mogensen's main argument the Basic Argument. The Basic Argument employs an example that Mogensen calls TRACKS, which is as follows:

TRACKS You discover a hiker with a large bag lying on the tracks. A runaway trolley is coming towards her and she will die in the event of a collision, thereby stopping the trolley. Your immediate inclination is to pull her to safety. However, you discover that doing so will allow the trolley to proceed on its path and run over five people who are located further up the track. ${ }^{7}$

Here is the Basic Argument itself:

1. If we should prevent optimific wrongings, you should stop me pushing the hiker off the bridge in FOOTBRIDGE*.

2. If you should stop me pushing the hiker off the bridge in FOOTBRIDGE*, you should pull the hiker to safety in TRACKS.

3. It is not the case that you should pull the hiker to safety in TRACKS. ${ }^{8}$

\footnotetext{
${ }^{7}$ Mogensen, 'Optimific Wrongs', p. 219.

${ }^{8}$ Slightly adapted from Mogensen, 'Optimific Wrongs', pp. 218-9.
} 
Therefore, it is not the case that we should prevent optimific wrongings.

The first premise is obviously true. Mogensen's defence of the second premise is that there are no morally relevant differences between the two cases. His defence of the third is as follows:

it seems to me that it would be seriously wrong to intervene in this case because of the manner in which this would implicate you in the death of the five. Here, the needs of the many outweigh the needs of the few. ${ }^{9}$

If these claims are correct, then, since the argument is valid, Mogensen's conclusion follows. We are not morally required to prevent optimific wrongings.

However, as I said, I don't think this argument is successful. There is a problem concerning the argument's scope: it targets a straw man. Moreover, even after the argument is refined so that the scope problem is overcome, its premises remain suspect. I discuss the problem about scope in the next section. I assess the premises in the sections after that.

\footnotetext{
${ }^{9}$ Mogensen, 'Optimific Wrongs', p. 219.
} 


\section{THE SCOPE OF THE BASIC ARGUMENT}

The Basic Argument's target appears to be very general: the view that we ought to prevent optimific wrongings. Indeed, since Mogensen treats this view as contrasting with the view that it is permissible to allow optimific wrongings, the target view appears to be that it is impermissible not to prevent optimific wrongings, i.e. that anyone who fails to intervene to prevent optimific wrongings acts wrongly.

But that would be a straw man. No one thinks that every optimific wronging that I could prevent is one that I act wrongly in failing to prevent. For one thing, there are rights which protect people from interference even with their wrongings. ${ }^{10}$ For instance, suppose that you are about to embark on an affair with someone, and that this would wrong your spouse. Still, your rights protect you from my preventative intervention. I don't act wrongly in failing to prevent the affair. A fortiori, I don't act wrongly in failing to prevent the affair if it's optimific. In general, since we don't act wrongly in respecting rights, we don't act wrongly in respecting rights to perform wrongings that happen to be optimific.

Even if we restrict ourselves to consideration of those wrongings that are not protected by rights, the pervasiveness of injustice and the nature of our obligations to fight it speak against any suggestion that there is a general prohibition on non-intervention. The obligation to fight injustice is most

\footnotetext{
${ }^{10}$ The classic discussion is Jeremy Waldron, 'A Right to Do Wrong', Ethics 92 (1981), pp. 21-
} 39. 
plausibly understood as an imperfect obligation, like other obligations of beneficence. It leaves us some discretion to determine how to discharge it. Accordingly, we must do something about injustice - we may not simply ignore it - but that does not mean that we must do something about every injustice. Nor does it mean that we must do as much as we possibly can to prevent injustice. For one thing, preventing injustice isn't the only thing that we can do about it; we can also rectify it and provide assistance to victims of it. For another, there are other imperfect obligations (e.g. the obligation to provide aid to the suffering, even when their suffering isn't the result of an injustice) that must be balanced with that one. ${ }^{11}$ Even a very demanding conception of the obligation to prevent injustice will not have it that a person acts wrongly in failing to prevent any injustice. Therefore, it won't have it that a person acts wrongly in failing to prevent any optimific injustice. ${ }^{12}$

${ }^{11}$ See Barbara Herman, 'The Scope of Moral Requirement', Philosophy \& Public Affairs 30 (2002), pp. 227-256.

${ }^{12}$ I suppose optimific injustices might be so few that it would in fact be possible for a person to intervene to prevent all of them. So it wouldn't follow from the permissibility of not intervening to prevent every injustice that it's permissible to fail to intervene to prevent all optimific injustices. But I doubt that optimific injustices really are so few in number, and in any case it would be a strange conception of the obligation to fight injustice that gave priority to fighting optimific ones in particular. 


\section{THE SHORTER ARGUMENT}

These observations do not deprive Mogensen's argument of interest. But they demonstrate that the interesting question it raises is not about the permissibility of failing to prevent optimific wrongings in general. It is about the permissibility of failing to prevent optimific wrongings in the more restricted range of cases that are exemplified by FOOTBRIDGE*. What distinguishes these cases is the size of the moral benefits consequent upon a course of action (or inaction; I'll assume this henceforth) that would otherwise seem to be strictly morally prohibited, such as diverting a runaway train towards a person on a side track, pushing a person off a bridge to her death, or standing idly by as someone else does the same thing when you could stop her at no cost to yourself. (By 'moral benefits' here I mean, roughly, what a virtuous person would care about insofar as she were morally motivated, e.g. saving innocent lives, or respecting important rights.) The moral benefits in these cases are so great that doubt is generated as to whether the course of action that would otherwise be prohibited is also prohibited in the particular circumstances at hand.

The kinds of case in question are familiar from discussions of the DDE. They are set up so that the only thing that seems remotely likely to explain why the otherwise prohibited course of action (turning the trolley towards a person on a side track, etc.) is permitted in the particular circumstances at hand is that pursuing that course of action brings about such great moral benefits. Consider POINTS, for example: 
POINTS A train is speeding down a track. Its brakes have failed. Five innocent strangers are trapped further down the track, and if you do nothing, the train will hit and kill them. There is a side track onto which you could divert the train by pulling a lever. If you do this, the strangers will be spared, but Valerie (another innocent stranger), who is trapped a little way down the side track, will be hit and killed. You have no other options. Fully aware of all this, you pull the lever. ${ }^{13}$

If the lives of the five were not at risk on the main track, it would be just obvious that you must not divert the train onto the side track. So nothing but the presence of the five and the value of saving them seems capable of explaining the permissibility of diverting the train, if it is permissible. Similarly, in FOOTBRIDGE* , if the five were not at risk, it would be just obvious that you must not stand idly by while the hiker is pushed off the bridge (remember that you can prevent her death at no cost to yourself). Other possible reasons that an agent might have for pursuing the otherwise prohibited course of action, such as mere dislike of or indifference to the person who will be sacrificed, or other prior commitments and ends (we may stipulate that you do not have

\footnotetext{
${ }^{13}$ N. Ann Davis, 'The Priority of Avoiding Harm', in Bonnie Steinbock and Alastair Norcross (eds.), Killing and Letting Die, Second Edition (New York, 1994), pp. 298-354, at 327; Thomson, 'The Trolley Problem', p. 1397. POINTS is a variation on a case originally described in Philippa Foot, 'The Problem of Abortion and the Doctrine of Double Effect', in her Virtues and Vices (Oxford, 1978), pp. 19-32, at 23 .
} 
other comparably morally urgent ends that require your attention at this moment), will not justify it; and since perfect knowledge is assumed, hesitation on the grounds of uncertainty is also not excluded. So, again, nothing but the presence of the five seems capable of explaining the permissibility of allowing the hiker to be pushed off the bridge, if it is permissible. Let me stress that my point at this stage is not that an agent must actually have the right intentions in order for it to be permissible for her to divert the train etc. It is merely that the only remotely plausible explanation of the permissibility of doing so will appeal to the moral benefits that this would secure. ${ }^{14}$

In any case, these are the kinds of case that the philosophers whose intuitions Mogensen cites have in mind. And indeed some of what Mogensen says suggests that his argument is really about them rather than about optimific wrongings in general. ${ }^{15}$ So let's drop the first premise of the Basic Argument and amend the second slightly so as to give the following Shorter Argument:

1. If you should stop me pushing the hiker off the bridge in FOOTBRIDGE* and make the analogous interventions in like cases, you should pull the hiker to safety in TRACKS.

${ }^{14}$ Thanks to an anonymous referee for suggesting the argumentative strategy I pursue in this paragraph.

${ }^{15}$ For instance: 'Whilst not immune to the pull of the intuition that one ought to intervene in FoOTbRIDGE* and in other cases of its kind, I want to challenge that conclusion in this article.' (Mogensen, 'Optimific Wrongs', p. 217.) 
2. It is not the case that you should pull the hiker to safety in TRACKS.

Therefore, it is not the case that you should stop me pushing the hiker off the bridge in FOOTBRIDGE* and make the analogous interventions in like cases.

Of course, the Shorter Argument has narrower scope than the Basic Argument, but it remains of interest, since its conclusion is disputed by the philosophers cited by Mogensen. In my view, it's not compelling, however. Both premises are suspect.

\section{WOULD PULLING THE HIKER TO SAFETY IMPLICATE YOU IN THE}

\section{DEATHS OF THE FIVE?}

In this section and the next, I consider the second premise of the Shorter Argument: the premise that it is not the case that you should pull the hiker to safety in TRACKS. In sections 7-8, I consider the first premise.

I think the second premise lacks adequate justification. As we saw, Mogensen defends it by appeal to the 'manner in which [pulling the hiker to safety] would implicate you in the death[s] of the five' in TRACKS. But it's not clear why pulling the hiker to safety would implicate you in any wrong-making way in the deaths of the five. I will examine and reject four suggestions designed to substantiate the claim that it would. 
Here is the first. Your pulling the hiker to safety is (we assume) causally sufficient in the circumstances for the deaths of the five. So we could say that your pulling the hiker to safety causally implicates you in the deaths of the five.

However, leaving the hiker on the tracks would be causally sufficient for her death, so you're causally implicated in someone's death whatever you do. And the numbers don't settle things here. Mogensen grants that in FOOTBRIDGE, you shouldn't push the hiker off the bridge, even though not pushing her off causally implicates you in the deaths of five, and pushing her off would causally implicate you in the death of only one. So the notion of causal implication doesn't explain why pulling the hiker to safety in TRACKS isn't required.

The second suggestion is that pulling the hiker to safety implicates your will in the deaths of the five in an objectionable sense. Contemporary discussions of cases such as FOOTBRIDGE do sometimes appeal to the idea that one's will is implicated in certain kinds of morally troubling treatment of others to explain the wrongness of certain courses of action and the contrast with the permissibility of similar courses of action in apparently analogous cases. So, for example, Thomas Nagel argues that what explains the wrongness of your actions in a case like FOOTBRIDGE is that

When I [inflict harm] intentionally I incorporate that evil into what I do: it is my deliberate creation and the reasons stemming from it are magnified and lit up from my point of view. ${ }^{16}$

\footnotetext{
${ }^{16}$ Thomas Nagel, The View from Nowhere (Oxford, 1986), p. 180.
} 
Nagel's proposal is that this kind of implication of one's will in evil tells against your intentionally throwing someone into the path of a runaway train even to save five others, and thus also explains the contrast between such cases as FOOTBRIDGE and such cases as POINTS. For in POINTS, the structure of the outcomes that face you is equivalent to that in FOOTBRIDGE, but the course of action that saves the five involves only foreseeing, rather than intending, the death of the one. So that death isn't 'incorporated into what you do' in the same way as it would be if it were intended. Other philosophers appeal to the idea that in FOOTBRIDGE but not in POINTS your will is implicated in the sense that you must regard the person whose death you bring about as 'material to be strategically shaped or framed by [your] agency, ${ }^{17}$ which violates a prohibition on treating others as mere means.

But your will isn't implicated in either sense in the death of the five if you pull the hiker to safety in TRACKS, assuming that you do so with the intention of saving the hiker rather than of bringing about the death of the five. The deaths of the five would be foreseen but they need not be intended: you could perfectly coherently hope that they might be saved even as you pulled the hiker to safety. So their deaths aren't incorporated into what you do in saving the

${ }^{17}$ Warren Quinn, 'Actions, intentions, and consequences: The Doctrine of Double Effect,' in his Morality and Action (Cambridge, 1993), pp. 175-193, at 190. Others appealing to this idea include Dana K. Nelkin and Samuel C. Rickless, 'Three Cheers for Double Effect', Philosophy and Phenomenological Research 89 (2014), pp. 125-158; Victor Tadros, 'Wrongful Intentions without Closeness', Philosophy \& Public Affairs 43 (2015), pp. 52-74. 
hiker, and neither must you regard them as material to be strategically shaped or framed by your agency.

The third suggestion that might be thought to explain why pulling the hiker to safety would implicate you in the deaths of the five is as follows. By pulling the hiker to safety you get involved in the situation, and so become implicated in the outcomes that your intervention produces. You get blood on your hands, as it were, whereas leaving the hiker on the tracks keeps you uninvolved and so unimplicated. In a similar way, if I pick a free newspaper up from the ground, I am implicated in its presence back on the ground again after I drop it, whereas I'm not implicated in its presence on the ground if I don't pick it up in the first place. ${ }^{18}$ However, precisely because TRACKS is one of the special range of cases that I highlighted in section 3, it is not like the newspaper case in this respect. The fact that innocent lives are at stake, the fact that you are uniquely positioned to determine who lives and who dies, and the presumed small size of the cost to you of saving the hiker mean that you're involved - you're morally entangled, as it were - whether you like it or not. It's because of this that any plausible explanation of the permissibility of allowing the wronging to go ahead in this and like cases will have to appeal to the great moral benefits of doing so, as I said above; the agent's other ends, or her indifference, for example, are not going to count as adequate justifications. So this suggestion doesn't work either.

\footnotetext{
${ }^{18}$ Thanks to Sandy Steel for suggesting this example.
} 
But the fourth and related suggestion is more promising. ${ }^{19}$ This is that by pulling the hiker to safety, you remove a barrier that is protecting the five from being killed, which makes their deaths your doing rather than merely something you allow to happen. By contrast, if you don't pull the hiker to safety, you merely allow her death; you don't kill her. In that sense, you are implicated in the deaths of the five if you save the hiker but not implicated in the death of the hiker if you leave her where she is.

By itself, this would not be enough to vindicate the second premise of the Shorter Argument (that it is not the case that you should pull the hiker to safety in TRACKS), since you must be not only implicated, but implicated in a wrong-making way. But consider: according to the Doctrine of Doing and Allowing (DDA), it's more difficult to justify a harmful doing than it is to justify a harmful allowing, all other things equal. So, it might be argued, although the numbers alone don't tell in favour of the course of action that saves the five (as FOOTBRIDGE shows), once we observe that saving the hiker involves killing the five, whereas saving the five involves merely letting the hiker die, it becomes clear that there can be no justification or excuse for pulling the hiker to safety.

However, it's not clear that pulling the hiker to safety would in fact be an instance of barrier-removal that counts as a killing of the five, rather than as a letting die. It is generally agreed that there are cases in which even knowingly removing a barrier that protects another from harm does not constitute a doing of harm. Consider, for instance, DUCK, in which Helen ducks to avoid being hit

\footnotetext{
${ }^{19}$ Thanks to two anonymous reviewers for making me see the need to address this
} suggestion. 
by an arrow that is heading towards her, knowing that as a consequence Chris, who is standing behind her and has no room to manoeuvre, will be hit and killed instead. ${ }^{20}$ Surely Helen does not kill Chris; she merely allows him to die. So the question is whether pulling the hiker to safety in TRACKS is like DUCK or, instead, more like a different case - SHIELD - in which Sophie grabs David's shield, knowingly leaving David helplessly exposed to the arrows that are heading for them both.

I think pulling the hiker to safety in TRACKS is more like DUCK than it is like SHIELD. This claim can be defended without settling the ethics of barrier removal in general. Let's begin with an analysis of DUCK. What seems to make DUCK an allowing rather than a doing is that Helen has strong, undefeated rights over the barrier to harm - i.e. her body - that she removes. Her body belongs to her, and her rights over it are not outweighed by Chris's claims of need, because Helen's claims in the context are just as strong. This explanation of what makes DUCK an allowing is common to several accounts of the DDA that differ in other respects, and so seems relatively uncontroversial. Thus, for example, Jeff McMahan argues that removing a barrier to harm counts as merely allowing the harm if and only if the agent provided the barrier and the

${ }^{20}$ Kai Draper, 'Rights and the Doctrine of Doing and Allowing', Philosophy E Public Affairs 33 (2003), pp. 253-28o, at 261. For more examples, see Foot, 'The Problem of Abortion and the Doctrine of Double Effect', pp. 19-32; Warren Quinn, 'Actions, intentions, and consequences: The Doctrine of Doing and Allowing', in his Morality and Action (Cambridge, 1993), pp. 149-174; Shelly Kagan, The Limits of Morality (Oxford, 1989), chapter 3; Jeff McMahan, 'Killing, Letting Die, and Withdrawing Aid', Ethics 103 (1993), pp. 250-279; Jonathan Bennett, The Act Itself (Oxford, 1995); Fiona Woollard, Doing and Allowing Harm (Oxford, 2015), chapter 4. 
barrier is either not self-sustaining or not yet operative. ${ }^{21}$ He makes it clear that if a person's body is the barrier in question, it satisfies this condition. ${ }^{22}$ Fiona Woollard argues that removing a barrier to harm counts as merely allowing harm if the barrier belongs to the agent, and she explicitly includes the agent's body as among those things that belong to him. ${ }^{23}$ Meanwhile, Kai Draper's rights-based alternative to the DDA distinguishes DUCK from cases such as SHIELD on the grounds that in cases such as DUCK, but not in cases such as SHIELD, the agent who removes the barrier does not infringe upon anyone's rights in doing so, since each of us has exclusive rights of self-ownership. ${ }^{24}$

Now, in TRACKS you do not have rights over the hiker's body, of course. So TRACKS is not like DUCK in that sense. But the hiker has rights over her body, and unless there is particular reason to think that she does not want you to pull her to safety, it seems appropriate to presume that she does, and so to regard your actions as a case of helping her to do something that counts as an allowing: you act, in effect, as her agent. ${ }^{25}$ As in any case of rescue, it is always possible that the rescuee would not in fact consent to be rescued, but surely the default

\footnotetext{
${ }^{21}$ McMahan, 'Killing, Letting Die, and Withdrawing Aid'.

${ }^{22}$ See his discussion of The Dutch Boy at 'Killing, Letting Die, and Withdrawing Aid', p. 257.

${ }^{23}$ Woollard, Doing and Allowing Harm, chapter 4.

${ }^{24}$ Draper, 'Rights and the Doctrine of Doing and Allowing'.

${ }^{25}$ This is the strategy that Woollard adopts at Doing and Allowing Harm, pp. 70-9. She is the only author I know of who explicitly addresses this type of case, though what Judith Jarvis Thomson says at p. 64 of 'A Defense of Abortion', Philosophy \& Public Affairs 1 (1971), pp. 47-66, suggests the same response. Compare also what McMahan says about the Involuntary Donor cases in 'Killing, Letting Die, and Withdrawing Aid'.
} 
position must be to assume that she does. And if her self-rescue would count as an allowing of the harm that would be consequent upon it, I submit that others rescuing her should also be thought of as allowing that harm to come to those others. So, I conclude, the second premise cannot be vindicated by appeal to the idea that pulling the hiker to safety is a killing of the five rather than a mere allowing of their deaths.

I can't see any other wrong-making sense in which you would be implicated in the deaths of the five if you pulled the hiker out of the way of the oncoming trolley. So I conclude that Mogensen's attempt to justify premise 2 of the Shorter Argument is not compelling.

\section{SHOULD YOU PULL THE HIKER TO SAFETY?}

However, even if pulling the hiker to safety in TRACKS is not a killing of the five, but only an allowing of their deaths, that's not enough to show that it's permissible to pull the hiker to safety. After all, the most that we could have established so far is that you face a choice between letting one die and letting five die. If both options are allowings, shouldn't the numbers settle things? And perhaps Mogensen could also appeal at this point to what he takes to be a shared intuitive reaction to TRACKS according to which you should leave the hiker where she is.

However, it is not clear that anyone who already thinks you should intervene to prevent the hiker from being pushed off the bridge in FOOTBRIDGE* is going to agree. Indeed, some of the very ideas of will-implication that we examined in the preceding section seem likely to explain why those who think 
you should intervene in that way in FOOTBRIDGE* may well disagree that the numbers should settle things in TRACKS.

Let me explain. Why might it seem that you must intervene to prevent the hiker from being pushed off the bridge in FOOTBRIDGE*? Well, as we saw in section 4 above, in FOOTBRIDGE*, assuming that you have full knowledge of the situation and no comparably important competing ends, the only purpose that seems remotely likely to explain why it's permissible not to save the hiker from being pushed off the bridge is the purpose of thereby saving the five on the tracks from their deaths. But if you fail to save the hiker for that reason, you leave her in the way of harm in order to bring about the end of saving the five. It is essential to the plan that you execute by not intervening that she be hit by the trolley, just as it's essential to your plan in the more familiar FOOTBRIDGE that the hiker there be hit by the trolley too. Unlike inaction that stems from ignorance - which is ruled out of this case ex hypothesi - your inaction here incorporates the evil of the hiker's death into what you do just as much as your action does in FOOTBRIDGE, even if (because it's an allowing rather than a doing) that tells against it less than it does in FOOTBRIDGE. And it also commits you to regarding her as a means to the end of saving the five. ${ }^{26}$ So in that sense your

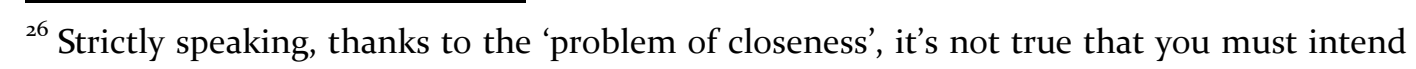
that the hiker be harmed, and so the specifically Nagelian explanation, which appeals to the evil of that harm, may in fact founder. But other accounts of intention-sensitivity that avoid the closeness problem also appeal to the hiker's essential involvement in your plan, so we can disregard this complication here. For further discussion, see Bennett, The Act Itself, chapter 11; Dana K. Nelkin and Samuel C. Rickless, 'So Close, Yet So Far: Why Solutions to the Closeness 
will is no less implicated in the hiker's death in the one case than it is in the other.

Suppose this is indeed the best explanation of the intuition that you ought to intervene to prevent the hiker from being pushed off the bridge in FOOTBRIDGE* ${ }^{*}$ (Let me be clear: I am not trying to offer a full defence of the account of intention-sensitivity that this explanation appeals to - that would take more space than I have here - but rather proposing it as the best explanation of the intuition about FOOTBRIDGE*.) In that case, it looks likely and defensible that if you have that intuition, you will also have the intuition that you ought to pull the hiker to safety in TRACKS. For we can say about TRACKS almost exactly what we just said about FOOTBRIDGE*. In TRACKS, the only purpose that seems remotely likely to explain why it's permissible to leave the hiker where she is is the purpose of thereby saving the five from their deaths. But if you leave the hiker where she is for that reason, you leave her in the way of harm in order to bring about the end of saving the five. It is essential to the plan that you execute that she be hit by the trolley, just as it's essential to your plan in FOOTBRIDGE that the hiker there be hit by the trolley too. Unlike inaction that stems from ignorance - which is ruled out of this case ex hypothesi - your inaction here incorporates the evil of the hiker's death into what you do just as much as your action does in FOOTBRIDGE, even if (because it's an allowing rather than a doing) that tells against it less than it does in FOOTBRIDGE. And it also commits you to regarding her as a means to the end of Problem for the Doctrine of Double Effect Fall Short', Noûs 49 (2015), pp. 376-409; Tadros, 'Wrongful Intentions without Closeness'. 
saving the five. So in that sense your will is no less implicated in the hiker's death in the one case than it is in the other.

Meanwhile, as we saw in section 5 above, if you pull the hiker to safety out of a concern for her life, your will is not implicated in the same way in the deaths of the five, which you may foresee but which need (and should) be no part of your intention in saving the hiker.

For those who think that the evil-incorporating nature of one's intention suffices, in this kind of case, to make its execution wrongful, this will be enough to show that you may not leave the hiker to be hit by the trolley. Others may think not that it's the evil-incorporating nature of the intention that makes its execution wrongful, but rather that only when one's intentions do not incorporate evil are the general prohibitions on failing to provide life-saving, low-cost assistance in certain situations weakened. But this kind of view won't help Mogensen either, since your intentions in failing to save the hiker wouldn't have the feature necessary for the prohibition to be weakened.

Thus Mogensen's modus tollens is simply going to be his opponent's modus ponens. As against this kind of reasoning, the only non-question-begging kind of reply that seems available to Mogensen is one that disputes either (a) the assumption that permissibility is intention-sensitive in these cases or (b) the degree to which the fact that not saving the one in these cases is an allowing rather than a doing weakens the prohibition on your acting in ways that contribute causally to the hiker's death. But Mogensen is not offering either 
kind of argument. Indeed, it seems that he hopes to bypass the need to do so by appealing to TRACKS instead. ${ }^{27}$

I conclude that the Shorter Argument is not, as it stands, compelling. There are reasons to reject the second premise (that it is not the case that you should pull the hiker to safety in TRACKS), and Mogensen's defence of it does not defeat those reasons. Of course, further investigations of (a) or (b) may yield more support for the second premise, but it would take us too far afield to pursue such investigations here. Instead, I turn now to consider Mogensen's defence of the first premise of the Shorter Argument, which is interesting in its own right.

\section{THE WRONG-PREVENTING PRINCIPLE}

The arguments I discussed in sections 5 and 6 pitted Mogensen against opponents who think you ought to pull the hiker to safety in TRACKS. Mogensen's defence of the first premise of the Shorter Argument targets a different set of opponents. Here is a reminder of that first premise:

1. If you should stop me pushing the hiker off the bridge in FOOTBRIDGE* and make the analogous interventions in like cases, you should pull the hiker to safety in TRACKS.

\footnotetext{
${ }^{27}$ Mogensen acknowledges ('Optimific Wrongs', p. 217) that the philosophers he cites don't take the DDA to justify non-intervention in FOOTBRIDGE*. But he doesn't engage with them on that score, choosing instead to offer the Basic Argument.
} 
Mogensen's opponents here are people who think you must intervene to prevent the hiker from being pushed off the bridge in FOOTBRIDGE* and yet share Mogensen's intuition that you need not (or perhaps must not) pull the hiker to safety in TRACKS. ${ }^{28}$ Mogensen thinks this position is incoherent, because the most plausible account of the morally relevant difference between TRACKS and FOOTBRIDGE* fails. I disagree.

The most plausible account of that difference appeals, Mogensen thinks, to

The Wrong-Preventing Principle (WPP) For any wrong action, there is some reason to prevent that action over and above those reasons associated with preventing harm to the victim(s). ${ }^{29}$

${ }^{28}$ For Mogensen's argument to go through, he needs to show only that you need not pull the hiker to safety in TRACKS. As we have seen, however, his defence of that claim appeals to the idea that it would be wrong to pull the hiker to safety. As against both claims, I have suggested reasons to think that it would be wrong not to pull the hiker to safety. In this section and the next, I consider the coherence of disregarding my suggestion and taking it to be morally required to intervene to prevent the hiker from being pushed off the bridge in FOOTBRIDGE* and yet not taking it to be morally required to pull the hiker to safety in TRACKS. My defence of the coherence of this position will not depend on the claim that it is required, rather than merely permissible, to leave the hiker on the tracks in TRACKS, so there is no need to clarify whether we are assuming one or the other. Thanks to an anonymous reviewer for pressing me to clarify this.

${ }^{29}$ Mogensen, 'Optimific Wrongs', p. 220. 
Since in FOOTBRIDGE* your non-intervention allows a wrong action (pushing the hiker off the bridge) to go ahead, whereas in TRACKS (presumably) it does not, WPP implies a reason to intervene in FOOTBRIDGE ${ }^{*}$ that it does not imply for TRACKS. If there is no such reason in TRACKS, that might be enough for the value of saving the five to make it permissible to leave the hiker on the tracks.

Why accept WPP? To my mind, the most promising account of the principle appeals to ideas about complicity. In some situations, my failure to prevent some wrong being done to you makes me complicit in the wrong, in the sense that it effectively expresses my endorsement of or at least acquiescence in it. And that compounds the original wrong. We have reason not to do that, reason not to throw our weight behind the mistreatment of others.

Now, there is also reason not to throw our weight behind non-wrongfully produced harm to others too. To do so is express a kind of indifference to their fate. That is a reason that favours pulling the hiker to safety in TRACKS just as the complicity reason favours intervening to prevent the hiker from being pushed off the bridge in FOOTBRIDGE*.$^{30}$ But, all other things equal, what's expressed by acquiescence in wrongful harm to others is worse than what's expressed by acquiescence in non-wrongfully produced harms to others. For acquiescence in wrongful harm to another is acquiescence in someone's being

\footnotetext{
${ }^{30}$ Note that the Wrong-Preventing Principle doesn't imply that for non-wrongful harmcausing processes, there is no reason to prevent such processes over and above those reasons associated with preventing harm to the victim(s), although I'm not sure whether the reason not to throw our weight behind the non-wrongfully produced suffering of others counts as a reason associated with preventing harm to the victim(s) or not.
} 
actively picked on, in her being viewed in the objectionable way that the perpetrator of the wrong views her, whereas acquiescence in non-wrongfully produced harm lacks that distinctively pointed feature. So the reason not to throw our weight behind non-wrongfully produced harm to others is weaker than the reason not to throw our weight behind the wrongful harm to others, all other things equal (a qualification that I'll take as read henceforth). ${ }^{31}$

I have been careful not to say that failure to prevent a wronging always makes me complicit in it. This is for the kinds of reasons I canvassed in section 3 above. Failure to prevent a wronging makes me complicit just when it expresses endorsement of or acquiescence in the wronging. So WPP is too general, just as the conclusion of the Basic Argument was too general. It's not the case that for any wronging, there is some reason to prevent that action over and above those reasons associated with preventing harm to the victim(s), because sometimes failure to prevent the wronging doesn't make anyone complicit in it. In fact, the kind of reasoning that offers the most promising account of WPP turns out to justify only a more restricted principle:

The Second Wrong-Preventing Principle (WPP2) For any wronging, if failure to prevent the wronging would express endorsement of or acquiescence in it, that is a reason to prevent the wronging over

${ }^{31}$ As Iason Gabriel pointed out to me, a further ground for WPP, which would reinforce the conclusion I reach in this section (though not in section 8), might be the moral harm that perpetrators of wrongs do to themselves by perpetrating the wrongs. 
and above those reasons associated with preventing harm to the $\operatorname{victim}(\mathrm{s})$.

WPP2 covers FOOTBRIDGE*. As that case is set up, the only morally acceptable purpose you could possibly have in failing to intervene to prevent the hiker from being pushed off the bridge would be that of saving the five, and nonintervention for that purpose requires acquiescence in the wronging of pushing the hiker off the bridge. You can't coherently hope that the hiker isn't pushed off the bridge, given that it is your only way of achieving your purpose in not intervening. If the reason we have not to throw our weight behind wrongful harm to others is taken to be sufficiently strong, your reason to save the five may not be sufficient to outweigh this reason.

Now, since the reason not to throw our weight behind non-wrongfully produced harm to others is weaker than the reason not to throw our weight behind wrongful harm, it takes less to outweigh the reason not to throw our weight behind non-wrongfully produced harm than the reason not to throw our weight behind wrongful harm. To illustrate: to your left, some bears are mauling Antigonus. You know that if you save Antigonus from them, the bears will head off and kill a group of unconscious shipwreck victims who are lying nearby. However, the group is just big enough that it is permissible for you not to intervene to save Antigonus (which you can do at no risk to yourself). To your right, some more bears are mauling Perdita. You know that these bears, too, will head off and kill the unconscious people if you pull Perdita away from them. Whereas no one is responsible for Antigonus's mauling (it is a simply a 
horrible accident), Perdita was wrongfully thrown to the bears on your right by Leontes. WPP2 implies that, all other things equal, you should intervene to save Perdita. ${ }^{32}$

The same line of argument implies, all other things equal, that the reasons favouring pulling the hiker to safety in TRACKS are weaker than those favouring preventing the hiker from being pushed off the bridge in FOOTBRIDGE*. So it would not be incoherent to take the view that you are required to intervene in FOOTBRIDGE* but not in TRACKS. (Though it would be a little surprising to discover these reasons' different weights turn out to make a difference precisely when the numbers and harms are as they are in these two cases.)

\section{DEFFENDING WPP2}

Mogensen has three objections against WPP. Do they defeat WPP2? I don't think so.

The first objection is as follows. WPP implies that

in some cases we should choose a course of action that provides a lesser benefit because it also ensures the prevention of a wrong: we leave people worse off for the sake of there being fewer wrong acts. This applies even with a single set of potential beneficiaries: if a group of people is afflicted by harms arising from some natural phenomenon and another kind of harm

${ }^{32}$ Given that what is at issue is something - endorsing or acquiescing in harm - that seems likely to be morally troubling in almost every realistic case, a clear illustration of the difference WPP2 can make to permissibility must inevitably be far fetched. 
arising from wrongful actions, [WPP] may require that we prevent the wrongful acts rather than mitigating the natural phenomenon even if this means making the beneficiaries all-things-considered worse off. ${ }^{33}$

In its general form, this objection is not obviously particularly damaging. It may be true that in some cases both WPP and WPP2 imply that we should choose a non-optimific course of action because that course of action also ensures the prevention of a wronging. But anyone who thinks that you ought not to push the hiker off the bridge in FOOTBRIDGE is already open to the possibility that non-optimific courses of action may be morally required, and Mogensen is willing to grant that, at least for the sake of argument.

So more needs to be said to show that the implication in question is problematic. What Mogensen says to illustrate the objection may help. He says WPP may imply 'that it is more important to improve the economic rights of women in developing countries than to protect the same women against malaria, even if the women would be significantly better off ... as a result of our attempts to reduce the incidence of malaria'. ${ }^{34}$ This sort of case does look more worrying for a defender of WPP or WPP2. To finesse it so that it clearly applies to $\mathrm{WPP}_{2}$ in particular, imagine a case in which if we chose not to improve the economic rights of women, that would be precisely because doing so was for some reason a means of bringing it about that they would all be significantly

\footnotetext{
${ }^{33}$ Mogensen, 'Optimific Wrongs', p. 223.

${ }^{34}$ Mogensen, 'Optimific Wrongs', p. 223.
} 
less vulnerable to malaria. In that case, not improving the rights would effectively be acquiescing in the ongoing wronging as a means to the benefit.

Now, I don't have very firm intuitions about this case, but at any event it seems to me that a defender of WPP2 can respond by stipulating that the reason the principle supplies to prevent a wronging is outweighed if the alternative renders the wronged parties better off. And this wouldn't be ad hoc. What motivates WPP2, I argued, was an idea about complicity in wronging and the attitude that it expresses: that we second the wrongdoer's treatment of the wronged party, and the presuppositions of her diminished moral status or value that go along with that. But when the wronging is acquiesced in precisely because it is the best outcome for the victim, the acquiescence may not express that attitude after all. And so WPP2 may cease to apply in such circumstances.

Mogensen's second objection is this: WPP implies that one has no obligation to intervene to prevent the hiker from being pushed off the bridge in a version of FOOTBRIDGE* in which the pushing of the hiker is going to be carried out by something other than a person, e.g. by a dog. Similarly, we have no reason to ensure that autonomous cars behave as they would if they had morally perfect humans at the wheel. What is more, acceptance of WPP suggests that if self-driving ambulances were widespread, and one came across an ambulance about to run over one innocent person in order to save the five people it was carrying, one should check to see whether the ambulance is self- 
driving or not in order to decide whether to intervene or not. But that doesn't seem right. ${ }^{35}$

A reasonable response for defenders of WPP or WPP2 is to deny that there is anything especially counterintuitive about distinguishing the non-wrongful pushing from the wrongful pushing cases. Consider a version of FOOTBRIDGE* in which the hiker is about to be pushed off the bridge by a bear and a version of TRACKS (which, for all we know, could be the version Mogensen has in mind in setting out that example) in which the hiker has come to be on the tracks because she was pushed there by a bear. The only distinction between these two cases that looks at all likely to make a moral difference is that in one you face the choice before the process that puts the hiker in harm's way has been completed, whereas in the other you face it afterwards. Elsewhere in his discussion, Mogensen argues that such distinctions make no moral difference. ${ }^{36}$ Given this, it should be no surprise that someone who finds it intuitive to suppose that you may leave the hiker on the tracks in TRACKS changes her judgment about FOOTBRIDGE* when the pusher is changed from a person to a bear.

What about the self-driving cars and ambulances? It is not obvious that we should think of these as we think of bears and other forces of nature. Most autonomous machines are programmed and put into operation by humans. It is at least arguable that responsibility for what they do can be assigned to

\footnotetext{
${ }^{35}$ Mogensen, 'Optimific Wrongs', pp. 223-224.

${ }^{36}$ See Mogensen, 'Optimific Wrongs', pp. 220-222.
} 
humans. ${ }^{37}$ So there is some reason to think we should do our best to ensure that self-driving vehicles do behave as if there is a morally perfect human at the wheel. That would suggest that there is no particular reason in this vicinity to check whether an ambulance is self-driving before we decide whether to intervene to prevent it running over one person as it saves the lives of five others.

However, we can imagine that self-driving ambulances might sometimes malfunction in ways that cannot be attributed to any wrongdoing on the part of their creators, so that it isn't plausible to think responsibility for what a malfunctioning ambulance does is to be assigned to humans. ${ }^{38}$ Given this possibility, WPP2 does seem to give us reason after all to check whether the self-driving ambulance is malfunctioning in order to decide whether to intervene.

At this point I bite the bullet: we may have such reason. But remember that for the reason supplied by WPP2 to make a difference, the numbers have to be just right: the case for intervening to prevent a non-malfunctioning ambulance running over someone on its way to hospital has to be so finely balanced (the

${ }^{37}$ See e.g. Thomas W. Simpson and Vincent C. Müller, 'Just War and Robot Killings', The Philosophical Quarterly (forthcoming), who argue that responsibility (although not blame) for what autonomous machines do is always attributable to humans. For the opposite view, see Andreas Matthias, 'The responsibility gap: Ascribing responsibility for the actions of learning automata,', Ethics and Information Technology 6 (2004), pp. 175-183; Robert Sparrow, 'Killer Robots', Journal of Applied Philosophy 24 (2007), pp. 62-77.

${ }^{38}$ Andreas Mogensen pointed this out to me. Compare Simpson and Müller, 'Just War and Robot Killings', pp. 10-11. 
saved/harmed ratio has to be just right) that weakening the case for intervening by subtracting the reason provided by $\mathrm{WPP} 2$ is enough to justify nonintervention. Given that such cases are going to be vanishingly rare, and given that decision-making time in real-life encounters with self-driving ambulances about to run people over is going to be extremely short, it is plainly not a plausible rule of thumb to check to see whether an ambulance is malfunctioning before deciding whether to intervene (at least on the assumption that the ambulances are built to comply with morally appropriate standards). This, I think, explains the seeming absurdity of the idea that we have reason to check. But suppose I tell you about a hypothetical case involving numbers with just the right balance, leaving it unspecified whether or not the ambulance (built to comply with appropriate standards) is malfunctioning, and I ask you for a policy for such cases alone. I don't think it so implausible to think you should ask me whether the ambulance is malfunctioning or not before giving your verdict.

Mogensen's final objection is that WPP gives us no reason to prevent optimific wrongings that prevent other wrongings of equal or greater magnitude. Suppose that the trolley in FOOTBRIDGE* were within the control of someone whose intention in driving it was to murder the five. Then, Mogensen says, 'our duty to intervene would evaporate'. ${ }^{39}$ But this is counterintuitive, and it's also surprising that a difference in the trolley should make such a moral difference to the permissibility of your intervention.

\footnotetext{
${ }^{39}$ Mogensen, 'Optimific Wrongs', p. 225.
} 
As far as I can tell, Mogensen's thought here is that the extra reason supplied by WPP to prevent the quintuple murder makes it permissible to push the hiker off the bridge, and thus the reason that WPP gave you to intervene in the version of FOOTBRIDGE* in which the trolley is not driven with murderous intent no longer applies, putting the case on a par with TRACKS (in which, Mogensen is assuming, it is permissible not to intervene).

I am not sure I understand this reasoning. It is not obvious to me that any extra reason supplied by the WPP to prevent the quintuple murder would be sufficient to outweigh the rights of the hiker. (And of course strictly speaking WPP doesn't imply that other reasons against intervention don't appear in the modified version of FOOTBRIDGE* even if it's true that the WPP-supplied reason evaporates.) But in any case the reasoning does not apply to $\mathrm{WPP}_{2}$. $\mathrm{WPP}_{2}$ doesn't supply an extra reason to push the hiker off the bridge to prevent the quintuple murder, because not pushing the hiker off the bridge wouldn't express acquiescence in the wrong perpetrated against the five. There is no sense in which the murder of the five need be welcomed by anyone as part of their execution of intentions that are governed by respect for the hiker's rights, because it is not essential to such intentions that the five be murdered. So it's not the case that the reason that WPP2 gave you to intervene in the version of FOOTBRIDGE* in which the trolley is not driven with murderous intent no longer applies, putting the case on a par with TRACKS. 


\section{CONCLUSION}

As against the Basic Argument, I've offered three objections. The first is that the argument's conclusion targets a position that no one holds. For no one thinks that, in general, we are required to prevent optimific wrongings. Still, two of the premises of the Basic Argument combine to support a weaker conclusion: that you may allow the sacrifice of the one in FOOTBRIDGE* and like cases to go ahead. And this conclusion is also of interest. (It is denied by two of the contemporary philosophers responsible for the most important work in this area.) However, both premises are suspect. There is reason to reject the second premise (that you may leave the hiker on the tracks in TRACKS). For leaving the hiker on the tracks in TRACKS involves regarding the hiker in a way that is morally impermissible. And the first premise (that if you should stop me pushing the hiker off the bridge in FOOTBRIDGE* and make the analogous interventions in like cases, you should pull the hiker to safety in TRACKS) depends upon the indefensibility of WPP or anything like it, such as WPP2. But, I argued, WPP2 is defensible. So even those who accept Mogensen's claims about the permissibility of leaving the hiker on the tracks in TRACKS need not accept the conclusion that allowing the hiker to be pushed off the bridge in FOOTBRIDGE* is permissible.

So must we intervene to prevent optimific wrongings? The considerations I advanced in section 3 tell against any conclusion so general. But they do not tell against a requirement to intervene to prevent optimific wrongings in the rarer cases employed to illustrate the applicability and limits of the DDE, such as FOOTBRIDGE. Even though non-intervention in those cases would be an allowing 
rather than a doing, it may involve complicity in the optimific wronging in prospect that is sufficiently morally problematic to justify intervention. ${ }^{40}$

thomas.sinclair@philosophy.ox.ac.uk

$4^{0}$ Thanks to Iason Gabriel, Chris MacLeod, Brian McElwee, Andreas Mogensen, Alison Hills, Adina Preda, Sandy Steel and Tom Simpson and three anonymous reviewers for Utilitas for their comments, suggestions and encouragement. 